\title{
Protection of Hydroxyl Groups as a Trimethylsilyl Ether by 1,1,1,3,3,3-Hexamethyldisilazane Promoted by Aspartic Acid as an Efficient Organocatalyst
}

\author{
Arash GHORBANI-CHOGHAMARANI*, Masoomeh NOROUZI \\ Department of Chemistry, Faculty of Science, Ilam University, P.O. Box 69315516, Ilam, Iran
}

\begin{abstract}
A wide variety of alcohols and phenols were protected as trimethylsilyl ethers using 1,1,1,3,3,3-hexamethyl disilazane catalyzed by aspartic acid as a non-toxic, metal-free, and green organocatalyst at room temperature in acetonitrile under mild and heterogeneous conditions. The procedure is operationally simple and the silylated product was obtained in high yield and purity.
\end{abstract}

Key words: alcohol; phenol; 1,1,1,3,3,3-hexamethyldisilazane; trimethylsilylation; protection

CLC number: O643 Document code: A

Received 24 November 2010. Accepted 6 February 2011.

*Corresponding author.Tel: +98-841-2227022; Fax: +98-841-2227022; E-mail: arashghch58@yahoo.com,a.ghorbani@mail.ilam.ac.ir This work was supported by the research facilities of Ilam University, Ilam, Iran.

English edition available online at Elsevier ScienceDirect (http://www.sciencedirect.com/science/journal/18722067).

The search for molecules that are able to catalyze reactions between other molecules is important to increase the efficiency of chemical reactions and to provide ecological and economical viable options for the consumption of chemicals [1]. When a chemical reaction is to be carried out selectively at one reactive site in a multifunctional compound the other reactive sites must be temporarily blocked [2]. Silyl ethers are a popular and promising protecting group of hydroxy functions in synthetic organic chemistry and a variety of silyl ethers have been developed to date [3-7]. However, the use of these silylating agents is limited by disadvantages such as harsh reaction conditions, scarcity and tedious purification processes. 1,1,1,3,3,3-Hexamethyldisilazane (HMDS) is a cost-effective and stable reagent and is one of the most widely used silylating agents for the trimethylsilylation of hydroxyl groups. The best advantage of this reagent is the quick isolation of the products from the reaction media because the by-product of the reaction is ammonia, which is easily removed from the reaction media. However, the low silylating power of HMDS is its main drawback. Therefore, to activate this reagent an appropriate catalyst should be used. Over the last decade many catalysts [8-15] have been used for this purpose but some of these procedures suffer from long reaction times, low product yields, heavy metal contamination, and catalyst toxicity.

\section{Experimental}

All chemicals and solvents were purchased from Fluka,
Merck, or Aldrich and used without further purification. All the products are known and were characterized by a comparison of their spectral (IR, ${ }^{1} \mathrm{H}$ NMR, or ${ }^{13} \mathrm{C}$ NMR) and physical data with authentic samples.

To a mixture of 4-bromobenzyl alcohol $(0.187 \mathrm{~g}, 1 \mathrm{mmol})$ and hexamethyldisilazane $(0.129 \mathrm{~g}, 0.8 \mathrm{mmol})$ in $\mathrm{CH}_{3} \mathrm{CN}$ $(10 \mathrm{ml})$, aspartic acid $(0.003 \mathrm{~g}, 0.02 \mathrm{mmol})$ was added and the mixture was stirred at room temperature for $7 \mathrm{~min}$ (reaction progress monitored by TLC). The reaction was then quenched with water $(10 \mathrm{ml})$ and $20 \mathrm{ml}$ of $\mathrm{CH}_{2} \mathrm{Cl}_{2}$ was added. The organic phase was then dried over $\mathrm{Na}_{2} \mathrm{SO}_{4}(3 \mathrm{~g})$. Evaporation of the solvent gave pure (4-bromobenzyloxy) trimethylsilane in a $90 \%$ yield.

\section{Results and discussion}

In a continuation of our studies into the application of new catalysts in organic functional group transformations [16-22], we disclose here a new, efficient, and mild procedure for the trimethylsilylation of a wide variety of hydroxyl groups using HMDS in the presence of a catalytic amount of aspartic acid as an efficient organocatalyst under mild and heterogeneous conditions at room temperature.

Initially, to find an appropriate solvent for this procedure we screened different solvents for the trimethylsilylation of 4-bromobenzyl alcohol with HMDS in the presence of a catalytic amount of aspartic acid. As is evident from Table 1, 4-bromobenzyl alcohol was silylated in acetonitrile faster than in the other solvents. Consequently, we decided to use 
Table 1 Trimethylsilylation of 4-bromobenzyl alcohol using HMDS and catalytic amounts of aspartic acid at room temperature in different solvents

\begin{tabular}{cccc}
\hline Entry & Solvent & Time $(\mathrm{h})$ & Yield $^{\mathrm{a}}(\%)$ \\
\hline 1 & acetonitrile & 0.12 & 90 \\
2 & chloroform & 24 & 66 \\
3 & dichloromethane & 12 & 87 \\
4 & $n$-hexane & 24 & $-^{\mathrm{b}}$ \\
5 & ethyl acetate & 20 & 77 \\
6 & acetone & 24 & 87 \\
\hline
\end{tabular}

Reaction conditions: substrate $1 \mathrm{mmol}$, HMDS $0.8 \mathrm{mmol}$, aspartic acid 0.02 mmol. ${ }^{a}$ Isolated yield. ${ }^{b}$ Trace conversion.

acetonitrile as a solvent for the protection of the hydroxyl group by HMDS and aspartic acid.

With optimal conditions in hand, we report here the protection of alcohols as trimethylsilyl ethers using HMDS in the presence of a catalytic amount of aspartic acid in acetonitrile at room temperature with good to excellent yields (Table 2).

The trimethylsilylated product was obtained in good to high yield and the work-up procedure is very simple. Aspartic acid is easily isolated by filtration and the pure product can be obtained by a simple distillation of the reaction solvent. As shown in Table 2, the amount of HMDS and catalyst depends on the nature of the alcohol.

To investigate the role of aspartic acid as catalyst, 4-nitrobenzyl alcohol was subjected to the trimethylsilylation reaction without the catalyst. However, the reaction was not complete and the silylated product was obtained in $72 \%$ yield after $300 \mathrm{~min}$ (Table 2, entry 3 ).

Also, our results show that unhindered alcohols are more reactive than hindered alcohols and this selectivity is shown

Table 2 Trimethylsilylation of alcohols $1 \mathbf{a}-\mathbf{1 v}$ to the corresponding trimethylsilyl ethers $2 \mathbf{a}-\mathbf{2} \mathbf{v}$ using HMDS in the presence of a catalytic amount of aspartic acid in $\mathrm{CH}_{3} \mathrm{CN}$ at room temperature

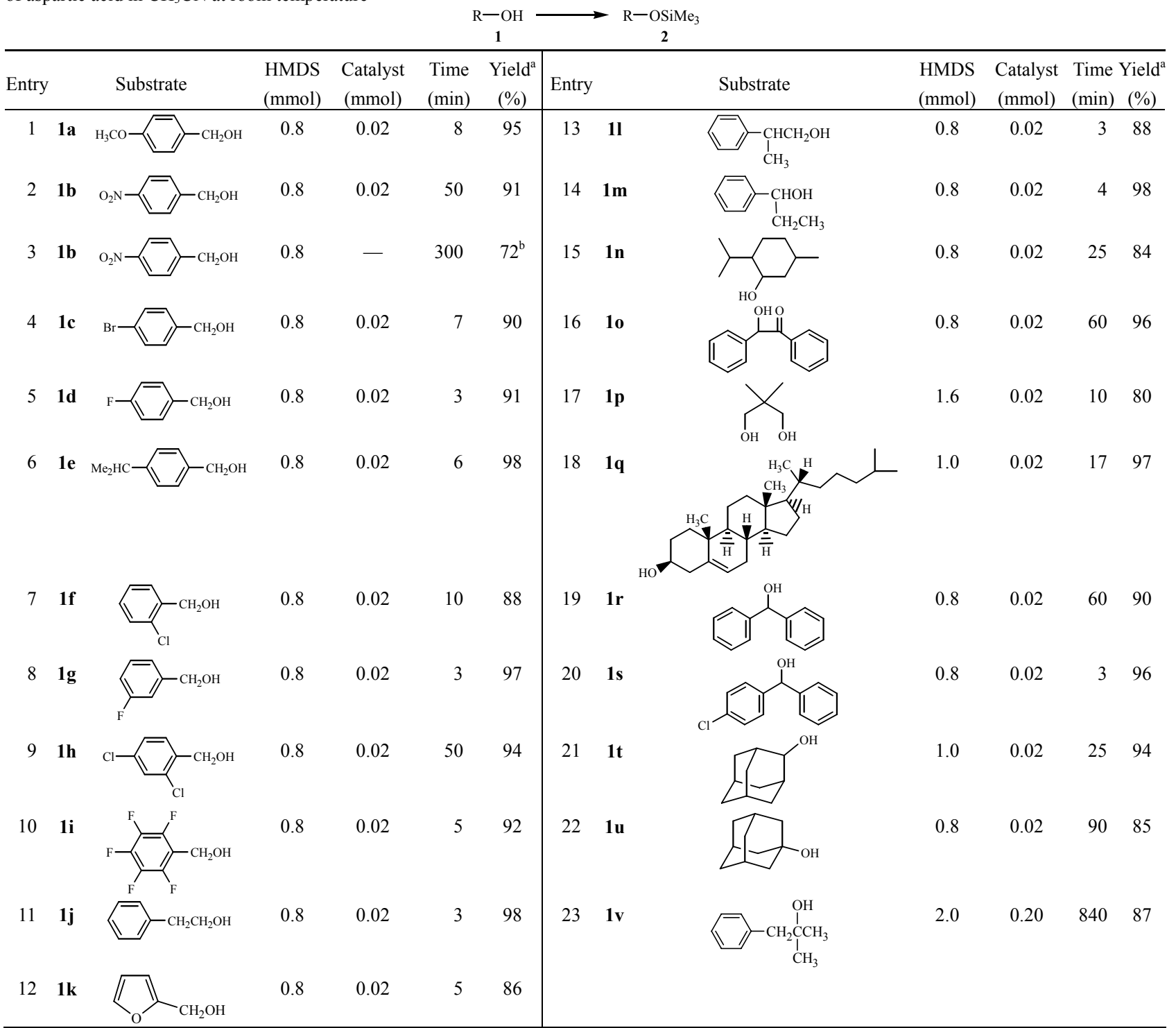

${ }^{\mathrm{a}}$ Isolated yield. ${ }^{\mathrm{b}}$ In the absence of catalyst. 


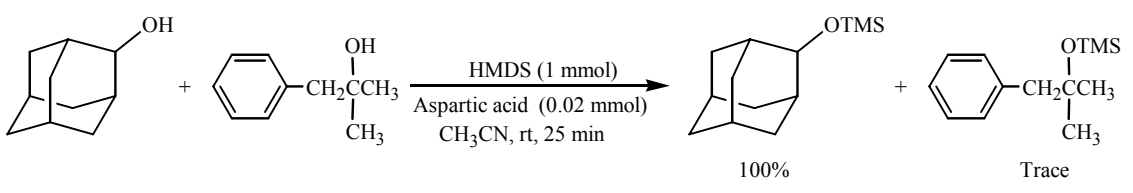

Scheme 1. Selectivity in the silylation reaction.

emphatically in Scheme 1.

To demonstrate the reactivity of the described system some hydrogen-labile substrates (in addition to alcohols) such as phenols, amines, and thiols were subjected to trimethylsilylation with HMDS in the presence of a catalytic amount of aspartic acid (Table 3). As shown in Table 3 the phenolic and alcoholic compounds were protected as trimethylsilyl ethers but the thiols and amines did not react with HMDS. Therefore, this procedure may be used for the silylation of hydroxyl groups in the presence of amino and thio functions.

Table 3 Trimethylsilylation of phenols, amines, and thiols to the corresponding trimethylsilylated products using HMDS in the presence of a catalytic amount of aspartic acid in acetonitrile at room temperature

Entry Substrate $\begin{gathered}\text { Time } \\ \text { (min) }\end{gathered}$

Reaction conditions: substrate $1 \mathrm{mmol}$, HMDS $0.8 \mathrm{mmol}\left({ }^{\mathrm{a}} 1.6 \mathrm{mmol}\right)$ aspartic acid $0.02 \mathrm{mmol}$. ${ }^{\mathrm{b}}$ Isolated yield.

A plausible mechanism for the silylation reaction is outlined in Scheme 2. Aspartic acid polarizes the $\mathrm{Si}-\mathrm{N}$ bond by hydrogen bonding. Polarization of the $\mathrm{Si}-\mathrm{N}$ bond converts HMDS to an activated silylating agent. On the other hand, hydrogen bonding between the hydroxyl group and the carboxylate moiety activates the hydroxyl group. The same sequence is apparent for the second alcohol molecule. Finally, the hydroxyl group silylate and ammonia is released as a by-product.

\section{Conclusions}

We developed a new catalytic protocol for the efficient

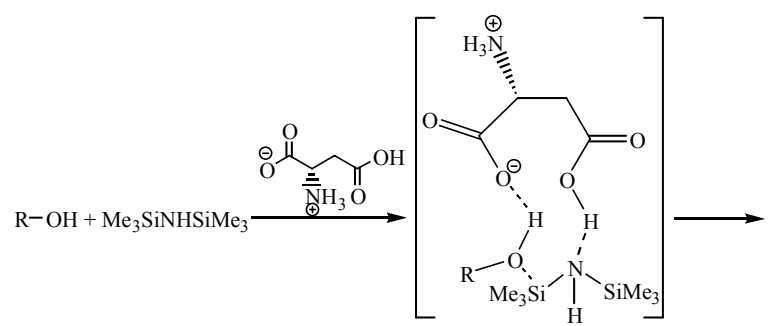

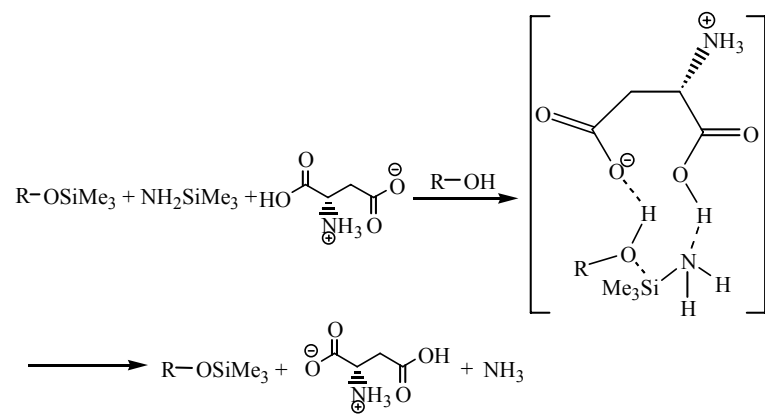

Scheme 2. Mechanism of the silylation of hydroxyl groups upon catalysis by aspartic acid.

trimethylsilylation of alcohol and phenol derivatives under metal-free, mild, and heterogeneous conditions. Short reaction times, metal-free content, good reaction yields, no environmental pollution, and simple work-up procedures make this method an excellent alternative for the protection of hydroxyl groups.

\section{References}

1 Togni A, Grützmacher H. Catalytic Heterofunctionalization. Weinheim: Wiley-VCH, 2001

2 Greene T W, Wuts P G M. Protective Groups in Organic Synthesis. 3rd Ed. New York: John Wiley \& Sons, 1999

3 Watahiki T, Matsuzaki M, Oriyama T. Green Chem, 2003, 5: 82

4 Ito H, Takagi K, Miyahara T, Sawamura M. Org Lett, 2005, 7: 3001

5 Iida A, Horii A, Misaki T, Tanabe Y. Synthesis-Stuttgart, 2005: 2677

6 Kim S, Kwon M S, Park J. Tetrahedron Lett, 2010, 51: 4573

7 Shirini F, Abedini M. J Iran Chem Soc, 2008, 5: S87

8 Khazaei A, Rahmati S, Rostami A. Helv Chim Acta, 2009, 92: 1434

9 Moghadam M, Tangestaninejad S, Mirkhani V, Mohammadpoor-Baltork I, Gharaati S. Polyhedron, 2010, 29: 212

10 Shirini F, Zolfigol M A, Paktinat M. Synthesis, 2006: 4252 
11 Shirini F, Zolfigol M A, Abri A R. Monatsh Chem, 2008, 139: 17

12 Curini M, Epifano F, Marcotullio M C, Rosati O, Costantino U. Synth Commun, 1999, 29: 541

13 Kurita K, Hirakawa M, Kikuchi S, Yamanaka H, Yang J. Carbohydr Polym, 2004, 56: 333

14 Jadhav V H, Kumar K S A, Chaudhari V D, Dhavale D D. Synth Commun, 2007, 37: 1363

15 Shirini F, Mollarazi E. Catal Commun, 2007, 8: 1393

16 Ghorbani-Choghamarani A, Zolfigol M A, Ayazi-nasrabadi R. J Braz Chem Soc, 2010, 21: 33

17 Ghorbani-Choghamarani A, Zeinivand J. J Iran Chem Soc,
2010, 7: 190

18 Ghorbani-Choghamarani A, Cheraghi-Fathabad N. Chin J Catal, 2010, 31: 1103

19 Ghorbani-Choghamarani A, Zolfigol M A, Rastegar T. Chin J Catal, 2009, 30: 273

20 Ghorbani-Choghamarani A, Hajjami M, Goudarziafshar H, Nikoorazm M, Mallakpour S, Sadeghizadeh F, Azadi G. Monatsh Chem, 2009, 140: 607

21 Ghorbani-Choghamarani A, Zamani P. J Iran Chem Soc, 2011, 8: 142

22 Ghorbani-Choghamarani A, Nikoorazm M, Goudarziafshar H, Shiri L, Chenani Z. Bull Korean Chem Soc, 2009, 30: 972 